\title{
Knowledge, attitudes, risk perceptions, and practices of adults toward COVID-19: a population and field-based study from Iran
}

\author{
Behnam Honarvar ${ }^{1} \cdot$ Kamran B. Lankarani $^{1} \cdot$ Ali Kharmandar $^{2,1}$ (1) $\cdot$ Fatemeh Shaygani $^{1} \cdot$ \\ Mohammadhassan Zahedroozgar ${ }^{1}$. Mohammad Reza Rahmanian Haghighi ${ }^{1} \cdot$ Sulmaz Ghahramani ${ }^{1}$. \\ Hossein Honarvar ${ }^{3} \cdot$ Mohammad Mehdi Daryabadi $^{3} \cdot$ Zahra Salavati $^{3} \cdot$ Seyed Mohammad Hashemi ${ }^{4}$. \\ Hassan Joulaei $^{5,1} \cdot$ Marziyeh Zare $^{1}$
}

Received: 25 March 2020 / Revised: 29 May 2020 / Accepted: 7 June 2020/Published online: 24 June 2020

(C) Swiss School of Public Health (SSPH+) 2020

\begin{abstract}
Objectives To determine peoples' knowledge, attitudes, risk perceptions, and practices to provide policymakers pieces of field-based evidence and help them in the management of the COVID-19 epidemic.

Methods This population-based survey was conducted using multi-stage stratified and cluster sampling in Shiraz, Iran. A total of 1331 persons were interviewed. The questionnaires were completed by face-to-face interviews. Univariable and multivariable (linear regression) data analyses were done using SPSS.

Results The participants answered $63 \%$ of questions regarding knowledge, and $78 \%$ of questions regarding practice correctly. Only, 4.8\% knew about common symptoms of COVID-19 and 7.3\% about warning signs that require referral to hospitals. Males, lower educated people, and elders had a lower level of knowledge and poorer practices. Knowledge was also lower in the marginalized (socially deprived) people. Knowledge and practices' correlation was 37\%. Overall, $43.6 \%$ considered themselves at high risk of COVID-19, and 50\% considered it as a severe disease. This disease had negative effects on most participants' routine activities (69.1\%). The participants preferred to follow the news from the national TV/ Radio, social networks, and foreign satellite channels, respectively.

Conclusions Encouragement of people to observe preventive measures and decreasing social stress, especially among males, lower educated people, elders, and marginalized groups, are highly recommended.
\end{abstract}

Keywords Knowledge $\cdot$ Attitude $\cdot$ Risk perception $\cdot$ Practice $\cdot$ Health belief model $\cdot$ COVID-19

Ali Kharmandar

ali.kh.sampad@gmail.com

1 Health Policy Research Center, Institute of Health, Shiraz University of Medical Sciences, Shiraz, Iran

2 Non-Communicable Disease Research Center, Fasa University of Medical Sciences, Fasa, Iran

3 School of Veterinary Medicine, Islamic Azad University, Kazerun, Iran

4 School of Rehabilitation, Shiraz University of Medical Sciences, Shiraz, Iran

5 Shiraz HIV/AIDS Research Center, Institute of Health, Shiraz University of Medical Sciences, Shiraz, Iran

\section{Introduction}

A recently detected novel coronavirus (nCoV), named as "SARS-CoV-2," causes "coronavirus disease 2019" (COVID-19) (WHO 2020b) with a clinical spectrum ranges from asymptomatic or mild respiratory symptoms to rapid death (Sahu et al. 2020; Tavakoli et al. 2020; WHO 2020b). COVID-19 was first reported in a hospital in Wuhan city, the capital of Hubei Province, China on 29th December 2019. Subsequently, the disease spread rapidly throughout the country. The first case of COVID-19 out of China was confirmed in Thailand on 13th January 2020. Iran reported the first confirmed case of COVID-19 in Qom, a city near Tehran; the capital city of Iran on 20th February 2020. World Health Organization (WHO) characterized this disease as a pandemic on 11th March 2020. 
Up to now, it has been spread to all continents other than Antarctica (Cheng and Shan 2020; WHO 2020d). Until 23rd March 2020, the number of confirmed infected people and the number of deaths because of this disease reached 332,930 and 14,510 worldwide, respectively, that shows a $4.3 \%$ mortality rate (WHO 2020a). Until 23rd March 2020, Iran has been ranked as the fifth country in the world in terms of confirmed COVID-19 cases (21,638 cases) with about $7.7 \%$ mortality (1685 cases), which is around two times of the global level (WHO 2020a). In the Fars which is the fourth-most-populous province of Iran, 552 confirmed cases of COVID-19 and 17 dead cases were reported till 23rd March 2020 (SUMS 2020). A risk assessment by WHO declared that there is a very high level of risk regarding this pandemic, which shows a need for immediate action (WHO 2020a). On the other hand, previous pieces of evidence about severe acute respiratory syndrome (SARS), Middle East respiratory syndrome (MERS), and Ebola showed that public knowledge, attitudes, and perceived risks have a determining role in controlling the epidemics (Almutairi et al. 2015; Choi and Kim 2018; Madhav et al. 2017; WHO 2020c; Yap et al. 2010). It should be mentioned that several strategies have been established at both national and local levels in our country and in line with WHO guidelines to improve people's knowledge and practices regarding COVID-19. Among these strategies were the closure of unnecessary businesses, public transportation, schools, and universities, publishing some preventive protocols, and educating people through national and local TV programs and social media. Therefore, this study was conducted to determine the level of knowledge, attitudes, risk perceptions, and practices of adults about transmission, prevention, treatment, and following the news about COVID-19, providing policymakers pieces of field-based evidence to help them in the management of this epidemic.

\section{Methods}

\section{Study setting}

This cross-sectional and population-based study was performed from February 2020 to March 2020, in Shiraz, in the southwest of Iran. Shiraz with a population of about 2 million is the capital city of Fars; the fourth widest and the fourth-most-populated province in Iran. The statistical population in this study was people aged at least 15 years. The sample size was calculated as 1200 , according to the frequency of correct knowledge of $50 \%$ in the pilot test that was conducted on 20 citizens, confidence interval of $95 \%$, error of 5\%, and design effect of 1.5 . We used a multi-stage stratified and cluster sampling to conduct this study. At first, we divided Shiraz into five geographical regions (North, South, Center, East, and West) and allocated an equal sample size for each region. For generalization of the results to the population of this city, sampling protocol was set in accordance with the Shiraz population's distribution in gender and age group based on the last National Population Census in 2016. Then, according to time-location sampling, we defined three main streets in each region. The questionnaires were completed in the morning, evening, and night in the selected streets. Only, residents of the defined regions were recruited, and if there were more than one person walking together on the street, only one of them was requested for an interview. There were not any other exclusion criteria, except non-willingness to participate in this study. Nineteen trained interviewers filled the questionnaires by face-to-face and in-personal interviews with selected persons.

\section{Data collection and quality assurance}

Initially, interviewers introduced themselves to the selected persons verbally and by showing their identification cards. Then, the aims of this study were explained to all participants while keeping at least $1-1.5 \mathrm{~m}$ physical distance from interviewees. After accepting to participate in this study, an interview was done with them. The questionnaire consisted of 52 questions: 6 demographic items, 17 knowledge-based, and 18 practice-based questions about transmission, prevention, and treatment of COVID-19, 10 questions regarding attitudes and risk perceptions, and 1 question about the source of COVID-19 news. There are several conceptual frameworks in health behavior research such as the health belief model (HBM) and the behavior change wheel (Ajzen and Fishbein 2005; Glanz et al. 2008; Michie et al. 2011). We selected the HBM as the main conceptual framework of this study and tried to design the questionnaire based on HBM asking some questions in different fields including knowledge, practice, risk perception, cues to action, facilitators, and barriers. For scoring of knowledge, we divided the questions into two subgroups; 8 questions included three options: completely correct, incompletely correct, and incorrect/not knowing the answer, while 9 questions included two options: correct and incorrect/not knowing the answer. The total score of knowledge was up to 25 . For scoring of practices, 13 questions were scored on a 5-point Likert scale and 5 questions were scored on a 2-point scale (yes/no answers) with the maximum score of 70 . We considered if the achieved score was less than $40 \%, 40 \%$ to $70 \%$, and more than $70 \%$ of total achievable scores in both knowledge and practice sections as "inappropriate," "roughly appropriate," and "appropriate," respectively. The face and content validity of the questionnaire, which had been designed in 
Persian, was confirmed by an expert panel consisted of experienced epidemiologists, virologists, and regional health policymakers in three sessions. The reliability of the questionnaire was calculated based on the pilot test. The Cronbach's alpha was $64.1 \%$ for the knowledge, $78.1 \%$ for the attitudes, $82.3 \%$ for the practices, and $65.5 \%$ for the whole questionnaire. Quality assurance was accomplished by supervision on the data collection process, data extraction, data entry to the software, and data analysis.

\section{Data analysis}

The data were entered into IBM SPSS 20 software. Univariable analysis was done using a $t$-test and analysis of variance (ANOVA). The correlation between knowledge and practices was evaluated by the Pearson correlation coefficient test. Multivariable analysis was done using linear regression after checking collinearity and VIF factors. In this study, $p<0.05$ was considered as the significant level.

\section{Results}

A total of 1331 persons participated in this study. Their mean of age was $36 \pm 13.9$ years, the female-to-male ratio was 1.1 , and $52.4 \%$ were married. Out of all participants, $45.7 \%$ were educated up to 12 years and the same percentage had a kind of job. About half of the responders were residents of the north and south of Shiraz (Table 1). The mean score of knowledge was $15.9 \pm 3.5$, while the mean score of practices was $55.1 \pm 8.1$, showing $63 \%$ and $78 \%$ of total achievable scores, respectively. Knowledge and practices had a correlation of $0.37(p<0.001)$. The most frequent correct responses to the knowledge questions were about properly wearing the face mask $(74 \%)$ and the least frequent ones were about common symptoms of COVID-19 (4.8\%) and warning signs that require referral to the hospitals (7.3\%) (Table 2). In terms of attitudes, $53.1 \%$ believed that preventive measures are highly observed in the community, while $68.6 \%$ believed that they themselves highly applied preventive measures. Moreover, $43.6 \%$ considered themselves at high risk of COVID-19, and $50 \%$ considered it as a severe and lethal disease. According to the answers by $69.1 \%$ of participants, this epidemic had highly negative effects on their routine activities (Table 3). The most frequent appropriate practice was the reduction of unnecessary out-of-home commuting $(72.1 \%)$, and the least frequent one was keeping a $1-\mathrm{m}$ distance from others (17.1\%). Furthermore, $63.5 \%$ of the participants had increased their drinking water, $17.7 \%$ traveled outside the city, and $19.1 \%$ were in contact with patients with at least one of the three symptoms of fever,
Table 1 Demographic characteristics of participants in a survey about COVID-19 from Iran, $2020(n=1331)$

\begin{tabular}{|c|c|}
\hline \multicolumn{2}{|l|}{ Characteristics } \\
\hline \multicolumn{2}{|l|}{ Age (year) } \\
\hline Mean \pm SD & $36 \pm 13.9$ \\
\hline $\operatorname{Median}(\min -\max )$ & $33(14-82)$ \\
\hline $15-19 n(\%)$ & $133(10)$ \\
\hline $20-29$ & $391(29.4)$ \\
\hline $30-39$ & $341(25.6)$ \\
\hline $40-49$ & $214(16.1)$ \\
\hline $50-59$ & $156(11.7)$ \\
\hline $60 \leq$ & $96(7.2)$ \\
\hline \multicolumn{2}{|l|}{ Gender n (\%) } \\
\hline Male & $629(47.3)$ \\
\hline Female & $702(52.7)$ \\
\hline \multicolumn{2}{|l|}{ Marital status n (\%) } \\
\hline Single & $554(41.6)$ \\
\hline Married & $697(52.4)$ \\
\hline \multicolumn{2}{|l|}{ Education n (\%) } \\
\hline Illiterate & $28(2.1)$ \\
\hline Lower than diploma & $217(16.3)$ \\
\hline Diploma & $364(27.3)$ \\
\hline Associate degree & $174(13.1)$ \\
\hline Bachelors & $355(26.7)$ \\
\hline Masters & $127(9.5)$ \\
\hline Doctorate & $23(1.7)$ \\
\hline \multicolumn{2}{|l|}{ Job status n (\%) } \\
\hline Unemployed & $468(35.2)$ \\
\hline Public sector's employee & $191(14.4)$ \\
\hline Private sector's employee & $418(31.4)$ \\
\hline Retired & $81(6.1)$ \\
\hline \multicolumn{2}{|c|}{ Geographical region of living in the city } \\
\hline North & $357(26.8)$ \\
\hline South & $302(22.7)$ \\
\hline Central & $208(15.6)$ \\
\hline East & $202(15.2)$ \\
\hline West & $262(19.7)$ \\
\hline
\end{tabular}

dry cough, or dyspnea during 2 weeks before this study (Table 4). Nearly half of the interviewees (46\%) declared that their first action was to refer to the medical doctors' clinics upon the occurrence of any suspected symptom of COVID-19, while $22.5 \%$ stated that their action was to refer to the public hospitals, the choice of $5.3 \%$ was to refer to the private hospitals, and $13.9 \%$ announced that they stayed at home for self-treatment. The univariable analysis in Table 5 shows that males had a lower level of correct knowledge and had more inappropriate practices about different aspects of COVID-19 than females. Elders also had a lower level of knowledge compared to other age 
Table 2 Knowledge of participants about COVID-19 in a survey from Iran, 2020

\begin{tabular}{|c|c|c|c|c|c|}
\hline No & Item & $\begin{array}{l}\text { Completely } \\
\text { correct } n(\%)\end{array}$ & $\begin{array}{l}\text { Incompletely } \\
\text { correct } n(\%)\end{array}$ & $\begin{array}{l}\text { Completely } \\
\text { incorrect } n(\%)\end{array}$ & $\begin{array}{l}\text { Don't know } \\
n(\%)\end{array}$ \\
\hline K1 & $\begin{array}{l}\text { Is it possible that someone gets COVID-19, while being } \\
\text { asymptomatic? }\end{array}$ & $815(61.2)$ & - & $290(21.8)$ & $208(15.6)$ \\
\hline K2 & $\begin{array}{l}\text { After being infected with COVID-19, how many days does it } \\
\text { take to show its symptoms? }\end{array}$ & $834(62.7)$ & $4(0.3)$ & $172(12.9)$ & $289(21.7)$ \\
\hline K3 & What are the transmission routes of COVID-19? & $767(57.6)$ & $536(40.3)$ & $3(0.2)$ & $14(1.1)$ \\
\hline K4 & What are the preventive routes of infection by COVID- $19 ?$ & $663(49.8)$ & $650(48.8)$ & $1(0.1)$ & $3(0.2)$ \\
\hline K5 & Which symptoms of COVID-19 are more frequent? & $64(4.8)$ & $1170(87.9)$ & $60(4.5)$ & $16(1.2)$ \\
\hline K6 & $\begin{array}{l}\text { In terms of COVID-19, what are the warning signs for going } \\
\text { to the hospital? }\end{array}$ & $97(7.3)$ & $945(71)$ & $236(17.7)$ & $33(2.5)$ \\
\hline K7 & $\begin{array}{l}\text { What phone number you call, if you have any questions } \\
\text { about COVID-19? }\end{array}$ & $362(27.2)$ & $0(0)$ & $377(28.3)$ & $443(33.3)$ \\
\hline K8 & $\begin{array}{l}\text { Which groups of people are at higher risk for mortality } \\
\text { following getting COVID-19? }\end{array}$ & $917(68.9)$ & $383(28.8)$ & $5(0.4)$ & $13(1.0)$ \\
\hline K9 & How the hands should be washed properly? & $985(74)$ & $0(0)$ & $294(22.1)$ & $23(1.7)$ \\
\hline K10 & What is the minimum time for proper hand washing? & $802(60.3)$ & $0(0)$ & $418(31.4)$ & $66(5.0)$ \\
\hline K11 & $\begin{array}{l}\text { Do you know the different types of face masks and their } \\
\text { uses? }\end{array}$ & $209(15.7)$ & $687(51.6)$ & - & $355(26.7)$ \\
\hline K12 & How long can you leave a mask on your face? & $948(71.2)$ & $136(10.2)$ & $145(10.9)$ & $72(5.4)$ \\
\hline K13 & How a face mask should be worn properly? & $996(74.8)$ & - & - & $287(21.6)$ \\
\hline K14 & How a used face mask should be disposed properly? & $849(63.8)$ & - & - & $453(34)$ \\
\hline K15 & How a used glove should be disposed properly? & $837(62.9)$ & - & - & $463(34.8)$ \\
\hline K16 & How COVID-19 patients should be cared at home? & $817(61.4)$ & - & - & $479(36)$ \\
\hline K17 & Is the flu vaccine protective against COVID-19? & $576(43.3)$ & - & $96(7.2)$ & $494(37.1)$ \\
\hline
\end{tabular}

Table 3 Attitudes and risk perceptions about COVID-19 in a survey from Iran, 2020

\begin{tabular}{|c|c|c|c|c|c|c|c|}
\hline No & Item & $\begin{array}{l}\text { Very high } \\
n(\%)\end{array}$ & $\begin{array}{l}\text { High } \\
n(\%)\end{array}$ & $\begin{array}{l}\text { Moderate } \\
n(\%)\end{array}$ & $\begin{array}{l}\text { Low } \\
n(\%)\end{array}$ & $\begin{array}{l}\text { Very } \\
\text { low } \\
n(\%)\end{array}$ & $\begin{array}{l}\text { None } \\
n(\%)\end{array}$ \\
\hline A1 & $\begin{array}{l}\text { To what extent preventive measures against COVID-19 are } \\
\text { observed in the community? }\end{array}$ & $292(21.9)$ & $415(31.2)$ & $413(31)$ & $116(8.7)$ & $48(3.6)$ & $19(1.4)$ \\
\hline A2 & $\begin{array}{l}\text { To what extent do you observe the preventive measures against } \\
\text { COVID-19? }\end{array}$ & $344(25.8)$ & $570(42.8)$ & $303(22.8)$ & $51(3.8)$ & $11(0.8)$ & $22(1.7)$ \\
\hline A3 & $\begin{array}{l}\text { To what extent, do you consider yourself at risk of getting } \\
\text { COVID-19? }\end{array}$ & $197(14.8)$ & $383(28.8)$ & $352(26.4)$ & $204(15.3)$ & $96(7.2)$ & $65(4.9)$ \\
\hline A4 & How much do you afraid of getting COVID-19? & $208(15.6)$ & $422(31.7)$ & $317(23.8)$ & $175(13.1)$ & $78(5.9)$ & $99(7.4)$ \\
\hline A5 & How much do you afraid of getting COVID-19 by your family? & 415 (31.2) & $417(31.3)$ & 265 (19.9) & $120(9.0)$ & $43(3.2)$ & $37(2.8)$ \\
\hline A6 & $\begin{array}{l}\text { How much do your family members are concerned about getting } \\
\text { COVID-19? }\end{array}$ & $362(27.2)$ & $442(33.2)$ & 314 (23.6) & $109(8.2)$ & $36(2.7)$ & $29(2.2)$ \\
\hline A7 & $\begin{array}{l}\text { To what extent do you think COVID-19 is a dangerous and } \\
\text { deadly disease? }\end{array}$ & 258 (19.4) & 407 (30.6) & $418(31.4)$ & $150(11.3)$ & $43(3.2)$ & 19 (1.4) \\
\hline A8 & $\begin{array}{l}\text { If you are suspected to have COVID-19, how prepared are you } \\
\text { to do the related test? }\end{array}$ & 624 (46.9) & 384 (28.9) & $171(12.8)$ & $60(4.5)$ & $32(2.4)$ & $15(1.1)$ \\
\hline A9 & $\begin{array}{l}\text { If you are suspected to have COVID-19, to what extent do you } \\
\text { hold yourself responsible for the health of others and follow } \\
\text { the preventive measures more precisely? }\end{array}$ & $841(63.2)$ & 278 (20.9) & 114 (8.6) & $37(2.8)$ & $16(1.2)$ & $12(0.9)$ \\
\hline A10 & $\begin{array}{l}\text { To what extent has COVID-19 had a negative influence on your } \\
\text { routine life? }\end{array}$ & 469 (35.2) & 451 (33.9) & $229(17.2)$ & $74(5.6)$ & $36(2.7)$ & $33(2.5)$ \\
\hline
\end{tabular}


Table 4 Practices of participants about COVID-19 in a survey from Iran, 2020

\begin{tabular}{|c|c|c|c|c|c|c|}
\hline No & Item & $\begin{array}{l}\text { Always } \\
n(\%)\end{array}$ & $\begin{array}{l}\text { Often } \\
n(\%)\end{array}$ & $\begin{array}{l}\text { Sometimes } \\
n(\%)\end{array}$ & $\begin{array}{l}\text { Rarely } \\
n(\%)\end{array}$ & $\begin{array}{l}\text { Never } \\
n(\%)\end{array}$ \\
\hline P1 & How often do you wash or disinfect your hands? & $676(50.8)$ & $437(32.8)$ & $158(11.9)$ & $24(1.8)$ & $13(1.0)$ \\
\hline P2 & $\begin{array}{l}\text { How often do you avoid touching your face and eyes with unwashed } \\
\text { hands? }\end{array}$ & 555 (41.7) & $466(35.0)$ & $225(16.9)$ & $30(2.3)$ & $27(2.0)$ \\
\hline P3 & How often do you use a face mask? & $397(29.8)$ & 407 (30.6) & $300(22.5)$ & $90(6.8)$ & $109(8.2)$ \\
\hline P4 & $\begin{array}{l}\text { How often do you use a face mask, paper tissue, or elbow when } \\
\text { sneezing, coughing, or having runny nose? }\end{array}$ & $470(35.3)$ & $517(38.8)$ & $224(16.8)$ & $60(4.5)$ & $31(2.3)$ \\
\hline P5 & $\begin{array}{l}\text { How often do you throw your used face masks and tissue papers in } \\
\text { separate bags and then in a bin? }\end{array}$ & $393(29.5)$ & $443(33.3)$ & $260(19.5)$ & $100(7.5)$ & $104(7.8)$ \\
\hline P6 & $\begin{array}{l}\text { How often do you regularly disinfect surfaces of personal objects and } \\
\text { places? }\end{array}$ & $335(25.2)$ & $461(34.6)$ & $315(23.7)$ & $111(8.3)$ & $70(5.3)$ \\
\hline P7 & How often do you shake hands with others? & $37(2.8)$ & $77(5.8)$ & $252(18.9)$ & $346(26)$ & $583(43.8)$ \\
\hline P8 & How often do you kiss others? & $20(1.5)$ & $62(4.7)$ & $164(12.3)$ & $314(23.6)$ & $745(56.0)$ \\
\hline P9 & How often do you hug others? & $23(1.7)$ & $61(4.6)$ & $162(12.2)$ & $312(23.4)$ & $744(55.9)$ \\
\hline $\mathrm{P} 10$ & How often do you keep at least $1-1.5 \mathrm{~m}$ distance from others? & $227(17.1)$ & $313(23.5)$ & $367(27.6)$ & $256(19.2)$ & $126(9.5)$ \\
\hline P11 & How often do you follow the news about COVID-19? & $416(31.3)$ & $478(35.9)$ & $239(18.0)$ & $104(7.8)$ & $52(3.9)$ \\
\hline P12 & $\begin{array}{l}\text { How often do you try to teach other people about the prevention of } \\
\text { getting COVID-19? }\end{array}$ & $343(25.8)$ & 460 (34.6) & 301 (22.6) & $122(9.2)$ & $69(5.2)$ \\
\hline P13 & $\begin{array}{l}\text { How often do you or your family cook eggs or meat properly before } \\
\text { consumption? }\end{array}$ & 902 (67.8) & 309 (23.2) & $48(3.6)$ & $30(2.3)$ & $7(0.5)$ \\
\hline
\end{tabular}

groups, while practices were nearly inappropriate in teenagers. Illiterate people had both a lower level of knowledge and practice. The married participants had lower knowledge but they had the same practices as singles. The retired persons had both a lower level of knowledge and poorer practices compared to the other types of occupations. The residents of the northern region had higher knowledge, and the residents of central and northern regions had more appropriate practices compared to the other regions of Shiraz. According to the multivariable analysis, knowledge about COVID-19 was lower in those with up to 12 years of education, people older than 60 years, in males, as well as in the residents of western and southern parts of Shiraz (Table 6). The practices were also poorer in the males, in the people with up to 12 years of education, and in the retired ones (Table 6). The participants preferred to follow the news about COVID-19 from different sources: mostly national TV/Radio (72.4\%), social networks (49.3\%), and foreign satellite channels $(41 \%)$.

\section{Discussion}

\section{Key findings}

Overall, knowledge and practices about COVID-19 in adults were roughly appropriate; however, the practices were not related to knowledge in two-third of the participants. Sheeran and Webb represented that there is a large gap between people's intention and behavior, including health behavior, in their study. They concluded that about half of people's intentions get translated into action which is similar to the results of the current study (Sheeran and Webb 2016). Most of the people did not know the common symptoms of COVID-19 and also did not know when they should refer to the hospitals. Therefore, unnecessary referrals to the limited hospitals in the current pandemic may cause burn out of the hospital staff, decreases the quality of healthcare services provided to the patients, and increases the carrier rate of COVID-19 in the community. The lower level of knowledge and observance toward COVID-19 were remarkable in the lower educated ones, elders, and males. Furthermore, nearly half of the population was worried about getting this disease. National media were the main sources selected by most participants to follow the news about COVID-19.

\section{Interpretation of the findings}

About two-thirds of people had correct knowledge regarding transmission routes of COVID-19, the technique of hand washing, and the correct use of protective equipment. However, their overall knowledge about preventive routes, common symptoms of COVID-19, indicative symptoms that require referral to hospitals, and phone numbers about COVID-19-related information was not 
Table 5 Univariable analysis of demographic determinants of knowledge and practices about COVID-19; concluded from a survey from Iran, 2020

\begin{tabular}{|c|c|c|c|c|c|c|}
\hline \multirow[t]{2}{*}{ Variable } & \multicolumn{3}{|c|}{ Knowledge (of 25) } & \multicolumn{3}{|c|}{ Practice (of 70) } \\
\hline & Mean \pm SD & Statistic & $P$ value & Mean \pm SD & Statistic & $P$ value \\
\hline \multicolumn{7}{|l|}{ Gender } \\
\hline Male & $15.5 \pm 3.7$ & \multirow[t]{2}{*}{$t=2.4$} & \multirow[t]{2}{*}{0.014} & $53.4 \pm 8.3$ & \multirow[t]{2}{*}{$t=6.7$} & \multirow[t]{2}{*}{$<0.001$} \\
\hline Female & $16.1 \pm 3.3$ & & & $56.5 \pm 7.7$ & & \\
\hline \multicolumn{7}{|l|}{ Age (year) } \\
\hline $14-19$ & $15.4 \pm 3.7$ & \multirow[t]{6}{*}{$F=23.2$} & \multirow[t]{6}{*}{$<0.001$} & $51.7 \pm 9.3$ & \multirow[t]{6}{*}{$F=6.5$} & \multirow[t]{6}{*}{$<0.001$} \\
\hline $20-29$ & $16.6 \pm 3.3$ & & & $55.4 \pm 8.6$ & & \\
\hline $30-39$ & $16.7 \pm 2.8$ & & & $56.5 \pm 7.3$ & & \\
\hline $40-49$ & $15.9 \pm 3.2$ & & & $55.0 \pm 7.5$ & & \\
\hline $50-59$ & $14.6 \pm 3.9$ & & & $54.9 \pm 7.3$ & & \\
\hline $60 \leq$ & $12.3 \pm 3.2$ & & & $53.4 \pm 7.9$ & & \\
\hline \multicolumn{7}{|l|}{ Level of education } \\
\hline Illiterate & $10.7 \pm 3.7$ & \multirow[t]{7}{*}{$F=33.1$} & \multirow[t]{7}{*}{$<0.001$} & $50.2 \pm 10.7$ & \multirow[t]{7}{*}{$F=11.6$} & \multirow[t]{7}{*}{$<0.001$} \\
\hline Under Diploma & $13.4 \pm 3.6$ & & & $51.6 \pm 8.3$ & & \\
\hline Diploma & $15.4 \pm 3.5$ & & & $54.5 \pm 8.1$ & & \\
\hline Associate Degree & $16.4 \pm 2.8$ & & & $56.9 \pm 8.0$ & & \\
\hline Bachelors & $17.2 \pm 2.6$ & & & $55.9 \pm 7.2$ & & \\
\hline Master & $17.2 \pm 2.7$ & & & $57.6 \pm 7.3$ & & \\
\hline Doctorate & $19.1 \pm 3.0$ & & & $60 \pm 7.5$ & & \\
\hline \multicolumn{7}{|l|}{ Marital status } \\
\hline Single & $16.1 \pm 3.6$ & \multirow[t]{2}{*}{$t=2.03$} & \multirow[t]{2}{*}{0.042} & $54.7 \pm 8.4$ & \multirow[t]{2}{*}{$t=-1.9$} & \multirow[t]{2}{*}{0.055} \\
\hline Married & $15.6 \pm 3.4$ & & & $55.6 \pm 7.6$ & & \\
\hline \multicolumn{7}{|l|}{ Job Status } \\
\hline Jobless & $15.4 \pm 3.6$ & \multirow[t]{4}{*}{$F=6.0$} & \multirow[t]{4}{*}{$<0.001$} & $55.2 \pm 8.3$ & \multirow[t]{4}{*}{$F=12.9$} & \multirow[t]{4}{*}{$<0.001$} \\
\hline Public sector's employee & $17.0 \pm 3.0$ & & & $57.5 \pm 6.4$ & & \\
\hline Private sector's employee & $16.0 \pm 13.2$ & & & $55.3 \pm 7.8$ & & \\
\hline Retired & $14.4 \pm 3.5$ & & & $53.1 \pm 7.7$ & & \\
\hline \multicolumn{7}{|l|}{ Region of living } \\
\hline North & $16.5 \pm 3.3$ & $F=5.01$ & 0.001 & $56.1 \pm 7.8$ & $F=4.4$ & 0.001 \\
\hline South & $15.4 \pm 3.6$ & & & $54.2 \pm 7.7$ & & \\
\hline Central & $15.8 \pm 3.4$ & & & $56.3 \pm 9.0$ & & \\
\hline East & $16.1 \pm 3.4$ & & & $54.3 \pm 8.4$ & & \\
\hline West & $15.2 \pm 3.6$ & & & $54.1 \pm 7.4$ & & \\
\hline
\end{tabular}

appropriate. Chen et al. conducted a study in Anhui province of China and showed that people had a high awareness of the main symptoms, transmission routes, using masks, hand washing, and treatment of COVID-19, while they had low awareness of atypical symptoms (Chen et al. 2020). Li et al. in their study in 31 Chinese provinces demonstrated that Chinese people had a moderate level of knowledge about COVID-19 (Li et al. 2020), while Thai people in the provinces close to China had poor knowledge about this disease (Srichan et al. 2020). Zhong et al. assessed the level of Chinese residents' knowledge in the early stages of the epidemic in China and concluded that they did not have a high level of knowledge (Zhong et al. 2020). According to our findings, more effective education should be provided to the males, elders, and lower educated ones, especially in the deprived regions. It is worth noting that COVID-19 causes more mortality among some of these groups such as elders. (Tavakoli et al. 2020).

In terms of the source of information, most of the people had followed COVID-19-related news via national TV/ Radios, social media, and foreign satellite channels, respectively. In the Anhui province of China, about $98 \%$ of participants declared that they received their information about COVID-19 from social media (Chen et al. 2020). It should be mentioned that tendency of people to use social media has been increased in the recent years due to easy access and appeal (Chitra and Senjith 2020); however, nonevidence-based information that is occasionally provided to people may mislead them and transfer some incorrect information to them. 


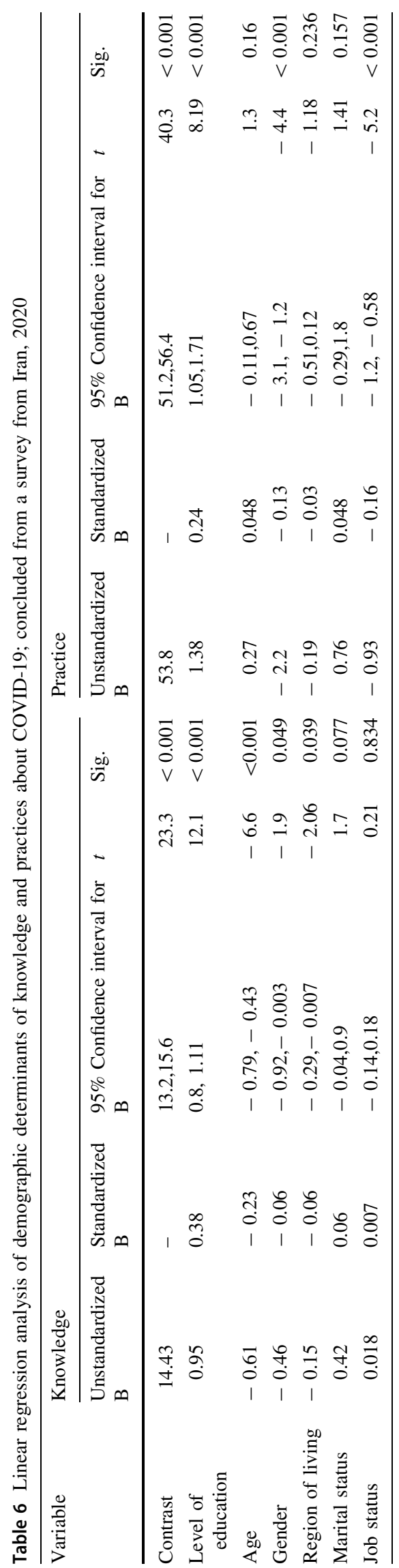

Attitudes of people as a mediator between their knowledge and practices have an important role for better controlling of epidemics of infectious diseases; they facilitate the process of changing people's behavior (Ajzen and Fishbein 2005). Also, risk perceptions can influence health-related behaviors and change risky behaviors (Glanz et al. 2008). Our study showed that only half of the participants perceived COVID-19 as a deadly disease, while in Thailand, about $70 \%$ considered it as a serious and dangerous disease (Srichan et al. 2020). Similarly, two other studies in China showed that the majority of people thought that COVID-19 outbreak was very severe and scary (Chen et al. 2020; Li et al. 2020). In our study, less than half of the people considered themselves at risk of COVID-19 and were worried about it, while a higher proportion were concerned about their family's health. According to Chen et al., more than $91 \%$ of people in Anhui province, China were scared of this disease (Chen et al. 2020), while $75 \%$ of Thai people thought that there was a high risk to get COVID-19 and two-third of them were worried about it (Srichan et al. 2020). Three-quarters of our respondents stated that the epidemic of COVID-19 had negative effects on their routine life, that was also mentioned by another study (Sadati et al. 2020). However, $\mathrm{Li}$ et al. had a different view and concluded that the frequency of sleep problems, aggression, and substance use became slightly lower after this outbreak ( $\mathrm{Li}$ et al. 2020). We also found that two-thirds of participants observed the preventive measures against COVID-19, while threequarters of them showed a good self-efficacy in their testing for COVID-19. Most interviewees felt a sense of responsibility and commitment to follow the preventive measures, more precisely, aiming to keep others healthy. Sirchan et al. showed that less than $15 \%$ of Thai people had strong attitudes toward COVID-19 prevention and its controlling (Srichan et al. 2020).

We found that nearly $70 \%$ of the people did the preventive measures to prevent the COVID-19, more than $80 \%$ of people washed their hands, and more than $60 \%$ used a face mask and removed it properly. However, nearly three-fourth of them had travel out of the city during two weeks before this study and more than half of them did not keep 1-m distance from others. These results were weaker than findings by Chen et al. in China, as over $91 \%$ of their studied people did the main ways of prevention including low gathering, less going out, and wearing masks (Chen et al. 2020). We also found that the practices to prevent COVID-19 were associated with gender and occupations, which is in line with the findings of Zhong et al. (2020). 


\section{Strengths, limitations, and recommendations}

Until now, population-based studies that have been conducted about public awareness, risk perceptions, and behavior toward COVID-19 are scarce; while most of them were mobile application-based, as a strength point, our research was a field-based study. As a limitation of this study, we could not extend its domain to the villages; however, this pandemic has influenced mostly the cities around the world. We also could not apply a completely random sampling due to administrative and ethical challenges; however, the time-location design of this study, its gender-age distribution protocol, and considering the design effect of 1.5 in the sample size calculation could to some extent overcome this weakness. We recommend to conduct similar studies in different countries to provide more pieces of evidence about public educational needs, to detect people with more needs for education and care, needs for controlling people's commuting within and out of cities, needs for equipment, hospitals' workloads, appropriate using of news and information's sources, and decreasing anxiety and stress at the family and community levels. Moreover, high-risk groups of communities, such as pregnant women, patients with chronic diseases, elders in nursing homes, prisoners, barracks staff, people with cognitive disabilities, disabled people, citizens of minorities, refugees and marginalized people including those who live in slums, socially deprived people, and those who do not have equal access to health and some other social facilities in comparison to other citizens, should not be overlooked in this pandemic as some of these groups were more regarded in the previous outbreaks (Lee et al. 2006).

\section{Conclusion}

Overall, knowledge and practices about COVID-19 in adults are roughly appropriate; however, in two-third of participants, practices were not related to their knowledge. Most of the people do not know about common symptoms of this disease and also do not know when they should refer to the hospitals. Therefore, unnecessary referrals to the limited hospitals in the current pandemic may cause burn out of the hospital staff, decreases the quality of healthcare services provided to the patients, and increases the carrier rate of COVID-19. Furthermore, continuous encouragement of people about the observance of preventive measures, especially in lower educated people, elders, and males is recommended, while high priority should be given to the residents of the deprived regions of the city.

Acknowledgement Conducting this study is due to the cooperation of the Shiraz people and the interviewers, we sincerely thank them all.
Funding This study was not funded by any organization.

\section{Compliance with ethical standards}

Conflict of interest The authors declare that they have no conflict of interest.

Ethical approval All procedures performed in studies involving human participants were in accordance with the ethical standards of the Shiraz University of Medical Sciences, with reference number: IR.SUMS.REC.1398.1384 and with the 1964 Helsinki declaration and its later amendments or comparable ethical standards. Moreover, for the protection of interviewers during data gathering, we trained them about the observance of standard precaution, and they were provided tools like antiseptic liquid, surgical masks, and latex gloves.

Informed consent Informed consent was obtained from all individual participants included in the study.

\section{References}

Ajzen I, Fishbein M (2005) The influence of attitudes on behavior. In: Albarracín D, Johnson BT, Zanna MP (eds) The handbook of attitudes. Lawrence Erlbaum Associates, Mahwah, pp 173-221

Almutairi KM, Al Helih EM, Moussa M et al (2015) Awareness, attitudes, and practices related to coronavirus pandemic among public in Saudi Arabia. Family Community Health 38:332-340. https://doi.org/10.1097/fch.0000000000000082

Chen Y, Jin Y, Zhu L et al. (2020) The network investigation on knowledge, attitude and practice about Novel coronavirus pneumonia of the residents in Anhui Province Zhonghua yu fang yi xue za zhi [Chinese journal of preventive medicine] 54:E004. https://doi.org/10.3760/cma.j.issn.0253-9624.2020. 0004

Cheng ZJ, Shan J (2020) Novel coronavirus: where we are and what we know. Infection 48:1-9. https://doi.org/10.1007/s15010-02001401-y

Chitra K, Senjith SA (2020) Knowledge management through social media-an empirical study on students in Chennai. Our Herit 68:60-64

Choi JS, Kim KM (2018) Infection-control knowledge, attitude, practice, and risk perception of occupational exposure to Zika virus among nursing students in Korea: a cross-sectional survey. J Infect Public Health 11:840-844. https://doi.org/10.1016/j.jiph. 2018.07.002

Glanz K, Rimer BK, Viswanath K (2008) Health behavior and health education: theory, research, and practice. Wiley, Hoboken

Madhav N, Oppenheim B, Gallivan M et al (2017) Pandemics: risks, impacts, and mitigation, chap 17. In: Jamison DT, Gelband H, Horton $\mathrm{S}$ et al (eds) Disease control priorities: improving health and reducing poverty, 3rd edn. The International Bank for Reconstruction and Development / The World Bank, Washington (DC). https://doi.org/10.1596/978-1-4648-0527-1_ch17

Lee DT, Sahota D, Leung TN et al (2006) Psychological responses of pregnant women to an infectious outbreak: a case-control study of the 2003 SARS outbreak in Hong Kong. J Psychosom Res 61:707-713. https://doi.org/10.1016/j.jpsychores.2006.08.005

Li J-B, Yang A, Dou K et al. (2020) Chinese public's knowledge, perceived severity, and perceived controllability of the COVID19 and their associations with emotional and behavioural reactions, social participation, and precautionary behaviour: a national survey. https://doi.org/10.31234/osf.io/5tmsh 
Michie S, van Stralen MM, West R (2011) The behaviour change wheel: a new method for characterising and designing behaviour change interventions. Implement Sci 6:42. https://doi.org/10. 1186/1748-5908-6-42

Sadati AK, Lankarani MHB, Lankarani KB (2020) Risk society, global vulnerability and fragile resilience; sociological view on the coronavirus outbreak. Shiraz E-Med J 21:e102263. https:// doi.org/10.5812/semj.102263

Sahu KK, Mishra AK, Lal A (2020) Comprehensive update on current outbreak of novel coronavirus infection (2019-nCoV). Annals Transl Med. https://doi.org/10.21037/atm.2020.02.92

Sheeran P, Webb TL (2016) The intention-behavior gap social and personality psychology. Compass 10:503-518. https://doi.org/ 10.1111/spc3.12265

Srichan P, Apidechkul T, Tamornpark R et al. (2020) Knowledge, attitude and preparedness to respond to the 2019 novel coronavirus (COVID-19) among the bordered population of northern Thailand in the early period of the outbreak: a cross-sectional study. Available at SSRN 3546046

SUMS (2020) Daily report of COVID-19,Fars. https://corona.sums. ac.ir/

Tavakoli A, Vahdat K, Keshavarz M (2020) Novel coronavirus disease 2019 (COVID-19): an emerging infectious disease in the 21 st century. ISMJ 22:432-450

WHO (2020a) Coronavirus disease (COVID-2019) situation reports. https://www.who.int/docs/default-source/coronaviruse/situation- reports/20200321-sitrep-61-covid-19.pdf?sfvrsn=f201f85c_2. Accessed 20 Mar 2020

WHO (2020b) Health topics, coronavirus. https://www.who.int/ health-topics/coronavirus. Accessed 24 Mar 2020

WHO (2020c) Report of the WHO-China joint mission on coronavirus disease 2019 (COVID-19) https://www.who.int/docs/ default-source/coronaviruse/who-china-joint-mission-on-covid19-final-report.pdf. Accessed 24 Feb 2020

WHO (2020d) WHO characterizes COVID-19 as a pandemic. https:// www.who.int/dg/speeches/detail/who-director-general-s-open ing-remarks-at-the-media-briefing-on-covid-19-11-march2020. Accessed 11 Mar 2020

Yap J, Lee VJ, Yau TY et al (2010) Knowledge, attitudes and practices towards pandemic influenza among cases, close contacts, and healthcare workers in tropical Singapore: a crosssectional survey. BMC Public Health 10:442. https://doi.org/10. 1186/1471-2458-10-442

Zhong B-L, Luo W, Li H-M et al (2020) Knowledge, attitudes, and practices towards COVID-19 among Chinese residents during the rapid rise period of the COVID-19 outbreak: a quick online cross-sectional survey. Int J Biol Sci 16:1745-1752. https://doi. org/10.7150/ijbs.45221

Publisher's Note Springer Nature remains neutral with regard to jurisdictional claims in published maps and institutional affiliations. 